\title{
The Transcription Factor XBP1 in Memory and Cognition: Implications in Alzheimer's Disease
}

\author{
Moustapha Cissé, Eric Duplan, and Frédéric Checler
}

Université Côte d'Azur, INSERM, CNRS, IPMC, teams Fondation pour la Recherche Médicale and Laboratory of Excellence (LABEX) Distalz, Valbonne, France

\begin{abstract}
X-box binding protein 1 (XBPl) is a unique basic region leucine zipper transcription factor that was isolated two decades ago in a search for regulators of major histocompatibility complex class II gene expression. XBP1 is a very complex protein that regulates many physiological functions, including the immune system, inflammatory responses and lipid metabolism. Evidence over the past few years suggests that XBP1 also plays an important role in pathological settings, since its activity as a transcription factor has profound effects on the prognosis and progression of diseases such as cancer, neurodegeneration and diabetes. Here we provide an overview of recent advances in our understanding of this multifaceted molecule, particularly in regulating synaptic plasticity and memory function, and the implications in neurodegenerative diseases, with an emphasis on Alzheimer's disease. Online address: http://www.molmed.org
\end{abstract}

doi: 10.2119/molmed.2016.00229

\section{INTRODUCTION}

Alzheimer's disease (AD) is a neurodegenerative disorder characterized by progressive and irreversible cognitive decline. It is the most common cause of dementia and affects over 44 million people worldwide. The molecular hallmarks of AD are amyloid plaques (extracellular deposits consisting of aggregated insoluble amyloid- $\beta[A \beta]$ ) and neurofibrillary tangles (intracellular filamentous aggregates of hyperphosphorylated tau) in brain regions critical for learning and memory function (1). The staggering financial impact on society associated with the direct and indirect costs of caring for those afflicted by AD make it urgent to find effective treatments. Indeed, in 2015 alone, Alzheimer's and other forms of dementia cost the US $\$ 226$ billion in medical treatment, nursing home facility and other related costs. By 2050, the overall annual cost of treating AD could reach \$1.1 trillion, making it more costly to address than other potentially deadly diseases like cancer and leukemia (according to a report published in 2015 by the Alzheimer's Association, titled "Changing the Trajectory of Alzheimer's Disease"). This review highlights some of the most recent developments in AD research involving $\mathrm{X}$-box binding protein 1 (XBP1), a transcription factor associated with the endoplasmic reticulum stress response. We begin with a brief review of synaptic structure and the concept of dendritic spine loss in AD and provide an update regarding the link
Address correspondence to Moustapha Cissé, IPMC CNRS, 660 route des Lucioles, 06560, Sophia-Antipolis, Valbonne, France, Phone: (33) 4 93953459, Fax: (33) 493953408 ; E-mail: cisse@ipmc.cnrs.fr; or Frédéric Checler, IPMC CNRS, 660 route des Lucioles, 06560, Sophia-Antipolis, Valbonne, France, Phone: (33) 493953460 , Fax: (33) 493953408 ; E-mail: checler@ipmc.cnrs.fr

Submitted November 21, 2016; Accepted for Publication December 23, 2016;

Published Online (www.molmed.org) January 4, 2017. between XBP1 and AD. We summarize recent evidence that local translation at the synapse may control XBP1 functional availability at dendritic spines. We review the data suggesting that $\mathrm{XBP} 1$ is protective against $A \beta$ neurotoxicity and regulates memory function. Finally, we consider how these pieces might fit together to suggest a mechanism by which XBP1 alleviates pathology in AD and the implications moving forward from a therapeutic strategy standpoint.

\section{Evidence for the Presence and Role of XBP1 in Dendritic Spines}

Synaptic connectivity and the dynamics of presynaptic (neurotransmitter release) and postsynaptic (receptor insertion and internalization) sites that regulate learning and memory processes are compromised in Alzheimer's disease (AD). Glutamate receptor-dependent synaptic plasticity is altered by exposure to oligomeric forms of $A \beta$ peptide in different systems (for review, see (2)). Studies have shown extensively that $\mathrm{A} \beta$ oligomers cause morphological abnormalities in the dendrites as well as a significant reduction in spine density $(3,4)$ and induce memory deficits in naive mice (5). Further, A $\beta$-induced loss of dendritic spines is a structural 
abnormality that alters the function of a large number of signaling molecules at postsynaptic sites $(2,6)$. Many of these molecules are critical elements responsible for shaping and maintaining anatomical structures on neurons and mediating signaling pathways that control neuronal communication. In recent years, numerous studies have identified several putative receptors for $A \beta$ oligomers, including $\alpha 7-n A C h R(7), \operatorname{RAGE}(8), \operatorname{PrP}^{\mathrm{c}}(9)$, mGluR5 $(10,11)$, insulin receptor (12), EphB2 receptor $(13,14)$, human LilrB2 (15), the p75 neurotrophic receptor (16) and reelin (17). Interaction of $A \beta$ oligomers with these receptors might constitute crucial events leading to morphological and functional changes of dendritic spines associated with cognitive impairment in $\operatorname{AD}(4,18)$. Thus, preserving the spines' dynamic and integrity is essential for the brain to develop synaptic networks capable of accurate information processing. Accordingly, tremendous efforts have been oriented toward therapeutic strategies aimed at circumventing A $\beta$ neurotoxicity by activation of signaling pathways $(13,19,20)$ or stimulation of neuronal hubs $(21,22)$ that selectively rescue spine density and memory function. In that context, $\mathrm{XBP} 1$, a key regulator of the endoplasmic reticulum (ER) stress response (23) that is highly expressed in the soma, axons and dendrites in neuronal systems, has emerged as a novel and promising molecule. Indeed, XBP1 activates a plethora of target genes involved in a variety of physiological functions, including neuronal plasticity $(19,24-26)$, suggesting an important role during the branching and maturation of developing neurons. Accumulation of unfolded or misfolded proteins in the ER leads to an ER stress response, which is characteristic of cells with a high level of secretory activity and is implicated in a variety of disease conditions such as AD. In response to ER stress, cells elicit an adaptive process called the unfolded protein response (UPR) to support cellular homeostasis and survival. In that context, $\mathrm{XBP} 1$ is a member of the CREB/ATF basic region-leucine zipper family of transcription factors that is ubiquitously expressed in adult tissues. In mammalian cells, it is activated by a post-transcriptional modification of its mRNA by inositolrequiring enzyme $1 \alpha$ (IRE1 $\alpha$ ), an ERlocalized proximal sensor of ER stress that is a Ser/Thr protein kinase and an endoribonuclease. IRE1 $\alpha$ releases a 26-nucleotide intron from XBP1 mRNA by splicing, causing a shift in the codon reading frame that leads to translation of the active form of XBP1, called XBP1s (23). XBP1s detaches from the membrane and transfers into the cytosol and nucleus of cells, where it acts as a transcription factor by directly binding to the promoter region of target genes in various cell types and functions $(24,25,27,28)$. Hence, XBP1 is involved in the regulation of various facets of biology, such as cardiac myogenesis, hepatogenesis, plasma cell differentiation, regulation of ER and golgi, and development of secretory tissues (24). Further, XBP1 regulates a number of UPR-unrelated processes, including glycolysis, gluconeogenesis, lipid metabolism, and DNA replication and repair (29). To the best of our knowledge, two knockout mouse lines have been generated to explore the function and biology of XBP1. Masaki et al. (30) generated XBP1-deficient mice to study cardiogenesis and showed that heterozygous mice for XBP1 exhibit no obvious abnormalities, whereas homozygous mice die at the embryonic stage due to cellular necrosis of cardiac myocytes. In addition, mice with a conditional disruption of XBP1 in the liver showed defects in hepatic lipid synthesis that was unrelated to its function in the ER stress response (31). XBP1 is expressed in the mammalian brain (32), but its expression pattern and function in neuronal systems have been sparsely investigated. Analysis of the spatiotemporal dynamics of XBP1 mRNA during development of the mouse central nervous system (CNS) showed wide expression in the brain at embryonic stages, while after birth, it is preferentially found in regions with abundant neuronal cell bodies, with the hippocampus being the most labeled brain structure (33). Much evidence suggests that XBP1 mRNA is translated within neurites and subsequently transported into the nucleus (33), thus reflecting a regulatory system that has been reported for other transcription factors $(34,35)$. Besides the neurites-to-nucleus translocation of mRNA, it is important to note that local protein synthesis in dendrites has also been described as a key mechanism contributing to enduring forms of synaptic plasticity $(36,37)$. The notion of dendritic protein synthesis originated with the discovery of synapse-associated polyribosome complexes (SPRCs), structures that are selectively localized beneath postsynaptic sites on the dendrites of CNS neurons $(38,39)$. In this location, SPRCs might be activated by electrical and/or chemical signals from the synapse, causing ribosomes, mRNA and other critical components of the translational machinery to dock selectively in the postsynaptic cytoplasm for local protein synthesis. Altogether, this evidence suggests that XBP1 translation and expression in dendrites is complex and might require additional regulatory systems that operate synergistically or in parallel to ensure tightly controlled gene expression in time and space. Although the underlying mechanisms regulating $\mathrm{XBP} 1$ function in neurons remain to be clearly established, its presence in dendrites and its ability to regulate a plethora of genes, including those involved in AD pathogenesis, have sparked the interest of researchers in the field. AcostaAlvear et al. (24) first reported that XBP1 is associated with amyloid precursor protein (APP) metabolism. Indeed, XBP1 controls genes that regulate the trafficking and processing of APP, including nicastrin and presenilin, two components of the $\gamma$-secretase complex (40). Further, XBP1 positively controls ADAM 10 promoter, with a strong correlation between XBP1 and ADAM10 mRNA levels in two distinct AD models and in humans (41). In addition, under some experimental manipulation that reproduces a stress condition, such as exposure of cells to exogenous $\mathrm{A} \beta$ oligomers, $\mathrm{XBP} 1$ can negatively 
regulate expression and activity of the aspartyl protease $\beta$-site APP cleaving enzyme 1 (BACE1) (42), the rate-limiting enzyme involved in the production of A $\beta$ peptide (43), by promoting the activity of the ubiquitin-ligase HRD1 (42). Thus, this interplay might fuel a negative signaling loop with $\mathrm{XBP} 1$ reducing BACE1 and A $\beta$. Consequently, this further reduces BACE1 expression/activity, since $A \beta$ has been shown to control BACE1 levels (42,44-46). However, one cannot exclude alternative signaling pathways involving p25/CDK5 (47) or LRP1 $(48,49)$. Similarly, overexpression of ATF6 and XBP1 induced HDR1 expression and reduced APP levels in a proteasome-dependent manner, with a subsequent decrease in $A \beta$ levels (50). Together, these experimental findings support the notion that XBP1 influences $A \beta$ levels, with subsequent neuroprotective effects. Consistent with this hypothesis, induction of DNJ-27, an ER luminal protein, by IRE1 $\alpha /$ XBP1 ameliorates many deleterious phenotypes associated with $\mathrm{A} \beta$ peptides in a worm model of $\mathrm{AD}$ (51). Another study reported that resveratrol, a polyphenol present in red wine, reduces $A \beta 1-42$-induced toxicity through activation of XBP1 in an Alzheimer's model of Caenorhabditis elegans (52). Moreover, XBP1 prevented the accumulation of free calcium by reducing a specific isoform of the ryanodine receptor in flies expressing $A \beta$ and neurons treated with $A \beta$ oligomers (53). However, the full extent of how XBP1 exerts these beneficial effects and which molecular pathways are involved are poorly understood. Overall, this data coupled with the high expression of XBP1 in neuronal structures and its capacity to control genes involved in neuronal connectivity strongly suggests that it plays a central role in synaptic plasticity and memory function.

\section{XBP1 Regulates Memory Function and Ameliorates AD-like Pathology}

The hippocampus represents a major brain region in the systematic storage and organization of memories. Morphological changes at the level of dendritic spines occur throughout life and underlie structural mechanisms that control synaptic function and efficacy. There is evidence that spine density correlates with learning and memory performance $(54,55)$. Dendritic spines are very dynamic structures with diverse shapes (56) that can be influenced by experimental manipulations. These manipulations trigger internal neuronal inputs from other brain regions or external environmental stimuli to impact their density, motility, morphology and activity in both physiological $(57,58)$ and pathological $(19,21)$ contexts. Synaptic changes related to neuronal activity have been extensively explored by using the enriched environment paradigm as a means to study the impact of neuritogenesis and spinogenesis on learning and memory performance (59). Interestingly, genes involved in neuronal structure and synaptic plasticity, along with XBP1, were modulated by enrichment training (60). The wealth of evidence indicating that $\mathrm{XBP} 1$ is involved in many physiological and pathological functions $(27,28,61-68)$ is clearly at odds with the relatively small amount of attention it has received with regard to its role in memory function. As of this writing, only two studies have investigated the role of XBP1 in neuronal plasticity. In one study (26), Martinez et al. addressed two issues, the consequences of manipulating $\mathrm{XBP} 1$ expression in naive mice and the mechanism by which XBP1 exerts its effects in the brain. In the first set of studies, the authors assessed XBP1 function in the brain by taking advantage of two mouse models, a neural-specific Xbp1 conditional knockout model ( $\left.\mathrm{XBP} 1^{\mathrm{Nes}-/-}\right)$ (69) and a transgenic model $\left(\mathrm{Tg}^{\mathrm{XBP} 1 \mathrm{~s}}\right)$ that expresses XBP1s in neurons exclusively (26). The behavior screen on XBP1 $1^{\mathrm{Nes}-/-}$ mice revealed poor performance relative to controls in diverse hippocampus- and amygdala-dependent memory tests.

Moreover, long-term potentiation (LTP), a complex long-lasting form of plasticity involving $\mathrm{Ca}+/$ calmodulin-dependent protein kinase (70), at Schaffer collaterals to pyramidal cell synapses was greatly impaired, with a significant reduction of basal synaptic transmission in $\mathrm{XBP}^{\mathrm{Nes}-/-}$ mice. Thus, genetic depletion of XBP1 in the CNS caused multiple deficits in synaptic plasticity and impaired learning and memory-related processes. On the other hand, $\mathrm{Tg}^{\mathrm{XBP} 1 \mathrm{~s}}$ mice showed enhanced LTP measures and increased basal synaptic transmission that translated into improved performance on the contextual fear-conditioning test. Altogether, these data indicate that XBP1 has overall beneficial effects on memory. This assumption was strengthened by similar results obtained by adenovirus-mediated delivery of XBP1 in the hippocampus of mice and rats (26). To look at the mechanisms involved in these remarkable effects of XBP1 in the brain, Martinez et al. screened genes of UPR expression and genes linked to learning and memory. They observed a significant reduction of $b d n f$ genes along with a moderate decrease of many other genes involved in neurotransmission and synaptic plasticity in $\mathrm{XBP}^{\mathrm{Nes}-/-}$ mice. Conversely, BDNF mRNA levels were significantly increased in the hippocampus of $\mathrm{Tg}^{\mathrm{XBP} 1 \mathrm{~s}}$ mice and in animals injected with adeno-associated virus (AAV) expressing XBP1. Further analysis revealed a consensus site for XBP1 binding to $b d n f$ promoter that controls BDNF transcription. Remarkably, reintroducing BDNF via gene therapy rescued synaptic plasticity and memory function in XBP1 $1^{\text {Nes-/- }}$ mice, suggesting that XBP1 exerts its beneficial effects in the brain through a regulatory loop involving IRE1 $\alpha$, XBP1 and BDNF. Generally consistent with the above findings, another study examined the role of XBP1 in the brains of naive mice and transgenic models of AD (19). The report describes a preventive paradigm, as $\mathrm{AD}$ transgenic mice had no apparent synaptic and memory deficits at the time of intervention. At a later time point, measures of spine density, synaptic plasticity and hippocampal-dependent memory revealed significant improvements in AD mice expressing XBP1 relative to controls (19). The remainder of the study focused on delineating the mechanisms by which 
$\mathrm{XBP} 1$ is beneficial in the brain and showed activation of Rho-GEF Kalirin-7 signaling, which has a major role in the regulation of synapse formation, maturation and maintenance by engaging Rac1 (71-73). Interestingly, Kalirin-7, which is controlled by XBP1s transcriptional activity, was reduced in distinct animal models and human AD brains, more likely by A $\beta$-toxic species (19). This observation is important because shRNA-mediated depletion of endogenous Kalirin-7 in naive mice recapitulated the main synaptic and memory deficits observed in the AD model, which supports an important role for XBP1s/Kalirin-7 signaling in neuronal plasticity and memory function under normal conditions. This notion is further supported by the observation that shRNA-mediated blockade of Kalirin-7 signaling prevented the beneficial effects of XBP1s in AD mice, whereas blockade of EphB2, which has a well-established functional connection with Kalirin-7 $(74,75)$, had no effect. In contrast, direct delivery of EphB2 in the hippocampus rescued memory in the same paradigm (19). Altogether, this suggests that Kalirin-7 mediates the beneficial effects exerted by XBP1 independently of EphB2. However, the possibility that XBP1 might be acting downstream of EphB2 remains to be determined. It should be pointed out that XBP1s, besides restoring spine density, lowered overall $A \beta$ levels in the hippocampus as well (19). In conclusion, this model implicates a dual mechanism wherein XBP1s synergistically promotes synaptic plasticity by fostering spine formation through Kalirin-7 signaling and lowers A $\beta$ levels. Although the mechanisms underlying the XBP1s-dependent decrease of $A \beta$ levels were not fully elucidated in that study, they may require recruitment and activation of enzymes that regulate $A \beta$ levels $(41,42,76-79)$ and/or APP metabolism/trafficking (40,80-82).

\section{Potential Mediators of XBP 1 Signaling in Neurons}

Dendritic spines are morphologically and functionally highly heterogeneous (57). Given the diversity of extrinsic and intrinsic factors controlling their structure, shape, dynamic, elimination and remodeling, it is not surprising that numerous molecules regulate their complex architecture and function $(83,84)$. There are three main aspects of modulating synapse function: (1) promotion of synaptic transmission by enhancing transmitter release or blocking transmitter degradation and/or reuptake, (2) facilitation of synaptic plasticity by changing neuronal activity, and (3) stimulation of synaptogenesis by promoting the growth of new terminals or strengthening the existing pre- and postsynaptic structures by neurotrophic factors (85). For instance, XBP1 modulates many molecules involved in spine morphogenesis and memory function, including but not limited to Cdk5 $(24,86), \operatorname{BDNF}(26)$ and Kalirin-7 (87). An interesting question that remains unresolved is whether those molecules are similarly activated by XBP1 and engaged through a sequential chain of events along the same signaling pathway. Alternatively, these proteins can be independently recruited and activated through different pathways based on the specific neuronal connection that is established and cellular activity that needs to be achieved. These possibilities are not mutually exclusive and might also depend on the nature and intensity of the neuronal stimulus and the complexity of the function that is initiated. Indeed, experimental evidence for the latter scenario has recently been obtained in an AD model, in which XBP1 activates Kalirin-7 to rescue spine density and memory while engaging an additional pathway that reduces $A \beta$ levels (19). These events seem to be controlled by XBP1 through two independent branches, because blockade of Kalirin-7 signaling induced spine loss and deficits in synaptic plasticity and memory but did not preclude $A \beta$ reduction. Thus, maintaining spine integrity and functionality, not necessarily reducing the levels of oligomeric $A \beta$ or other potential neurotoxins such as C99 (88) and tau (89), is the sine qua non of neuronal plasticity and proper brain function in AD pathology. Furthermore, $A \beta$ oligomers affect a myriad of proteins at synapses, some of which are of paramount importance to the structure and plasticity of dendritic spines. Consequently, therapies based solely on a toxin-reducing approach, without associating a synaptic repair strategy by rescuing these critical proteins, would most likely be unsuccessful, particularly later on in the syndrome, when their function is altered and the integrity of spines is compromised. This was made even more evident by reports of clinical studies that showed effective reduction of $A \beta$ levels with concomitant reduction of amyloid plaque pathology but failed to improve the clinical outcome $(90,91)$. However, this reasoning is an oversimplistic explanation of AD etiology, since one has to specifically target the neurotoxin that is the most likely determinant of the syndrome to significantly ameliorate the pathology. Indeed, $\mathrm{AD}$ is a syndrome that involves dysregulated homeostasis on various fronts, likely resulting from a complex interplay between genetic, epigenetic and environmental factors. Furthermore, major epigenetic mechanisms involving DNA methylation, DNA demethylation, noncoding RNAs and chromatin remodeling might mediate interactions between genetic and environmental risk factors or directly interact with disease-specific pathological factors in AD (92-94).

Cdk5 is a member of the cyclindependent kinase family, which has been implicated in drug addiction, pain signaling, microtubule dynamics, and learning and memory formation $(95,96)$. Cdk5 is abundant in neuronal cells and is activated by complexing with p35 or p39 protein. It was recently reported that Cdk5 is required for the development and maintenance of dendritic spines in the mouse hippocampus (97). Furthermore, a conditional knockout mouse model of p35 exhibited spatial learning and memory impairments and reduced anxiety-like behavior through a cdk5-dependent pathway resulting from a decrease in the dendritic spine density of CA1 pyramidal neurons and defective 
long-term depression induction in the hippocampus (98). Cdk5 also controls memory function via regulation of surface NR2B (99). Importantly, TrkB phosphorylation-deficient mice displayed impaired spatial memory and compromised hippocampal LTP. These deficits were caused by an inability of TrkB receptors to be phosphorylated and interact with Rac1 for dendritic spine remodeling and reveals the importance of Cdk5 for LTP and spatial memory formation (86). Interestingly, abnormal Cdk5 activity has been implicated in AD pathology (100-103).

On the other hand, XBP1 can promote neurite outgrowth in neurons $(33,104)$ and enhance memory function in healthy mice (26) through regulation of BDNF, a member of the neurotrophin family (105). BDNF is ubiquitously expressed in the brain and has a wide range of neurotrophic properties that are mediated by the TrkB receptor. BDNF regulates synaptic plasticity in the brain (106-111), which in turn promotes synaptic growth (112-114). Interestingly, a report showed that the kinetics of TrkB activation by BDNF is a determining factor in cell signaling, with variable effects on spine structure and function (115). More evidence obtained by using knockout models revealed that BDNF signaling positively influences synaptic growth by fostering synapse formation, axonal branching, spine motility and dendritic growth (116-119). These significant changes have profound and long-lasting effects on synaptic plasticity, learning and memory function. Indeed, genetic and/or pharmacological manipulations of either BDNF or TrkB levels impaired (120-125) or ameliorated (126-130) neuronal plasticity and hippocampusdependent memory. BDNF has been implicated in a vast array of neurological disorders, including AD (85,131-136). Interestingly, a recent study showed that BDNF delivered after disease onset reversed pathology in an AD model (137). BDNF administration in the entorhinal cortex compensated for genetic, molecular and behavioral parameters of age-related neuronal atrophy and synapse loss in aged rats and nonhuman primates (137). What is more, a human genetic polymorphism in the gene encoding BDNF has been linked to abnormal brain structure, hippocampal activity and memory in humans (138-140) and to several psychiatric disorders (141-145). On a similar note, a polymorphism in the XBP1 promoter has been linked to a risk of AD (146). Collectively, these findings indicate that BDNF exerts substantial protective effects on the neuronal circuitry involved in AD and deserves to be further investigated as a mediator of XBP1 signaling and a potent therapeutic target across many neurodegenerative disorders.

Kalirin-7 also participates in XBP1 signaling and memory formation (19). In adults, Kalirin-7 is the major isoform in mature neurons, whereas Kalirin-9 and Kalirin-12 are primarily found at lower levels in peripheral tissues (87). Genetic disruption of Kalirin-7 reduced spine density and induced several motor and behavior deficits (71,147-149). Depletion of Kalirin-7 also impairs synaptic plasticity, probably through alteration of glutamate receptors and Rac1 signaling $(150,151)$. Rac1 is a downstream mediator of Kalirin-7 that controls the structural and functional plasticity of spines (152-154) and memory function $(155,156)$. Intriguingly, a recent study described a three-molecule model in dendrites that characterizes the spatiotemporal coordination of Rac1, RhoA and Cdc42 controlling the structural plasticity (sLTP) of spines (157). This model represents the BDNF-TrkB-Rac1 signaling that enables synaptic crosstalk during sLTP induction in spines. Although Kalirin-7 and BDNF have not been studied alongside each other with regard to memory function, evidence in the literature suggests that the two might be intricately linked through XBP1 activity-dependent regulation of spine plasticity. Indeed, BDNFdependent neurite outgrowth was abrogated by pharmacological blockade of TrkB or Kalirin-7 activity, and ablation of the Kalirin-7 gene abolished activation of Rac1 in response to BDNF stimulation (158). Hence, one would expect a blockade of Kalirin-7 signaling to abolish the rescue of memory function elicited by BDNF (26). Alternatively, a disruption of BDNF signaling would likely reduce or prevent XBP1-dependent amelioration of AD-like pathology (19). In vivo and in vitro studies have demonstrated that oligomeric $A \beta$ alters BDNF expression/function by downregulating its transcripts or impairing axonal transport, with subsequent adverse effects (159-165). Oligomeric A $\beta$ also reduces BDNF secretion by dendritic cells in humans, thereby decreasing neurotrophic supports for neurons and causing brain damage (166). An important aspect to consider is that expressing XBP1 in the brain promoted BDNF (26) or Kalirin-7 (19) signaling, with beneficial outcomes in spine density and memory. These observations led to the intuitive interpretation that XBP1 levels might be reduced in AD models and/or human patients. Surprisingly, endogenous XBP1 was undetectable in AD models that produced high levels of oligomeric $A \beta$ or in human brains postmortem (19), whereas neurons exposed to $A \beta$ oligomers showed a significant increase of XBP1 levels $(42,167)$. These discrepancies likely reflect a compensatory mechanism triggered by acute exposure to $A \beta$ oligomers, whereas chronic exposure to these neurotoxins, which is more reflective of the in vivo situation, causes an overdrive and collapse of the system. Direct evidence for such fluctuations comes from a recent study showing transient XBP1 activation at early time points in pathology followed by a decrease across different ages and AD models, as well as in humans (41). Notwithstanding the considerable knowledge of XBP1 biology, we do not yet know to what extent the various mediators of XBP1 signaling function through common, distinct or partly overlapping mechanisms. For that reason, future research efforts should determine the exact spatiotemporal sequence of events that controls XBP1-dependent amelioration of memory function and protection against AD-like phenotypes. 


\section{Therapeutic Implications of the Concept that XBP1 Protects Against AD-like Pathology}

AD has profound effects on patients and families and also represents a tremendous financial burden on the health care system. AD and Parkinson's disease, the two most prevalent neurodegenerative diseases, are estimated to have cost over $\$ 600$ billion worldwide in 2010 alone. This is staggering, particularly in light of predictions that the number of worldwide AD cases will triple by 2050 . Despite many years of research and advancements in basic and clinical research, there is no effective cure to treat neurological disorders associated with aging. Therefore, now more than ever, there is an urgent need to develop new and effective treatments for AD. Typically, two therapeutic approaches can be envisioned to tackle the conundrum of a given pathology: (1) the disease-modifying therapy or toxin-reducing approach targets the etiology of a disease and relies on early intervention to counteract the adverse effects of a given toxin, with the goal of significantly slowing or halting the course of the disease; and (2) the symptomatic therapy or palliative approach intervenes later on in the syndrome to transiently and mildly ameliorate symptoms and relieve pain and discomfort, with no effect whatsoever on the underlying causes and progression of the disease. Therefore, it is evident that a toxin-reducing approach could have better outcomes in AD pathology, which presents multiple clinical signs associated with complex cellular and network alterations. However, it is extremely challenging in general to start an early intervention for a given neurodegenerative disease due to the lack of reliable and sensitive biomarkers. At the time of diagnosis, clinical signs and symptoms are usually apparent, and an effective therapy would require combining symptomatic and disease-modifying approaches. Synaptic failure is a predominant feature in AD, and alteration of neuronal connectivity and spine loss are correlated with memory performance $(168,169)$.
Indeed, conventional wisdom holds that an increase in $A \beta$ load damages neuronal networks composed of memory engram cells. Therefore, the intuitive reasoning is that reducing $A \beta$ levels should protect synapses, ameliorate neuronal plasticity and translate into beneficial effects on memory function. Thus, interventions that ameliorate spine density and plasticity also boost memory function (170-172). Conversely, manipulations that reduce neuronal connectivity and spine density subsequently alter memory $(173,174)$. Therefore, targeting mechanisms that could stabilize and protect or repair and reestablish neuronal contacts and at the same time reduce $A \beta$ levels could be an optimal and efficacious strategy against AD pathology, as it was in an animal model (19). However, one should not overlook evidence that $A \beta$ has many physiological functions through regulation of synaptic activity (for review, see (175)) and control of genes as a transcription factor $(44,45,48)$. On this basis, XBP1 has the advantage of ameliorating neuronal plasticity and connectivity through both $A \beta$-dependent and -independent pathways, leading to an overall amelioration of memory function (19). Giving hope to future efforts, even partial expression of XBP1 has benefits, since only about $60 \%$ of neurons were infected in the CA1 and dentate gyrus (19), which is typical for this type of gene therapy procedure $(13,19,176,177)$. This also supports the idea that it is not necessary to normalize molecular alterations in every cell and brain region to significantly improve memory, as long as there are enough neurons to form active networks supporting essential brain functions. However, this type of approach needs be associated with effective tools to allow early diagnosis in the clinic, which currently are sorely lacking. Hence, researchers have focused on means to specifically promote synaptogenesis and/or spinogenesis in a subset of neurons or confined areas of the brain through diverse approaches, including oral or peripheral administration of molecules (170,178-183), optogenetic activation $(21,58,184-186)$, epigenetic mechanisms $(179,187)$, gene therapy $(19,188-193)$ and genetic depletion $(6,9,194,195)$. These approaches have shown great efficacy, at least in experimental models, in restoring spine density and memory function. Therefore, a combination of factors that positively regulate spine dynamics and neuronal connectivity or block $A \beta$ interaction with molecules that mediate its adverse effects could be efficient and should continue to be explored as a strategy to stop or delay cognitive decline in AD. For instance, future investigative steps should determine whether XBP1 is protective across various AD models and is as efficient in a curative paradigm. XBP1 can be activated upon administration of BDNF, and vice versa, in neuronal cell systems $(33,104)$ or in rodents $(26,196)$. This well-established functional relationship between XBP1 and the BDNF-TrkB pathway and the role of BDNF as a synaptogenic molecule in synaptic plasticity and synaptic growth should be fully taken advantage of and translated into effective therapies for AD pathology. However, this has been challenging due to several factors. For instance, use of AAV in the clinic has proven difficult due to host immunogenicity to the virus and limited biodistribution $(197,198)$. More recent approaches utilizing human mesenchymal stem cells (MSCs) that have been genetically engineered to produce BDNF have shown beneficial outcomes in a Huntington disease model (199). Importantly, some pharmaceutical companies, namely Atherys, SanBio and Brain Storm Therapeutics, finalized several MSC therapy-based phase II clinical trials involving ischemic stroke and amyotrophic lateral sclerosis patients and reported no adverse effects whatsoever (200). Furthermore, modulating the IRE1 $\alpha-X B P 1$ pathway with small-molecule compounds could be a promising approach for disease therapy (201), since various studies have reported that XBP1 protects against oligomeric forms of prion protein or $\alpha$-synuclein $(167,202-204)$. Nonetheless, the majority of these molecules are inhibitors that selectively 
block the IRE1 $\alpha$-XBP1 pathway $(205,206)$ because of its implication in several cancer pathologies, including breast (62) and pancreatic (207) cancers. Although there has not been extensive effort to identify compounds that specifically activate XBP1, quercetin, a flavonol commonly found in vegetables, fruits, nuts and grains in association with sugars, phenolic acids and alcohols, was identified as a compound that activates the RNase activity of IRE1 $\alpha$ on XBP1 splicing/activation and elicits a number of signaling pathways (208). For instance, quercetin attenuates glutamate-mediated excitotoxicity caused by excessive and dysregulated activation of glutamate receptors and/or transporters (209). This is an important observation, since evidence suggests that glutamate-induced excitotoxicity contributes to the neuronal injury and dysfunction in AD (210). Indeed, chronic exposure of organotypic hippocampal slices to oligomeric $A \beta$ caused excitotoxicity through an increase of glutamate levels in and around the synaptic cleft, resulting in desensitization of glutamate receptors and altered synaptic plasticity $(211,212)$. It should be noted that memantine, an uncompetitive N-methyl-d-aspartate (NMDA) antagonist, protected against axon neurodegeneration and glutamate-induced excitotoxicity caused by $\mathrm{A} \beta$ peptide (213) and ameliorated symptoms in human AD (214). Another interesting feature of quercetin is its capacity to inhibit tau hyperphosphorylation, through SIRT1 $(215,216)$ or alternate pathways $(217,218)$, that occurs primarily in vulnerable brain regions in $\mathrm{AD}$ and other tauopathies $(89,219,220)$. Quercetin also displays antiamyloidogenic properties, illustrated by its ability to reduce BACE1 and $A \beta$ levels in mice (217), prevent $A \beta$ aggregation $(221,222)$, promote autophagy $(221,223)$ and bind to BACE1 catalytic core as an inhibitor (224). On the other hand, quercetin enhances the effect of neurotrophic factors such as NGF (225) and BDNF (226) to foster neuronal survival and neurite outgrowth, with tangible amelioration of memory function in animal models of AD (227-231) and in humans (232). However, other clinical trials failed to report beneficial effects of quercetin on cognitive function (233). This discrepancy might be explained by the timing of the intervention. Indeed, the former study was conducted on earlystage AD patients, whereas the latter involved severe AD cases.

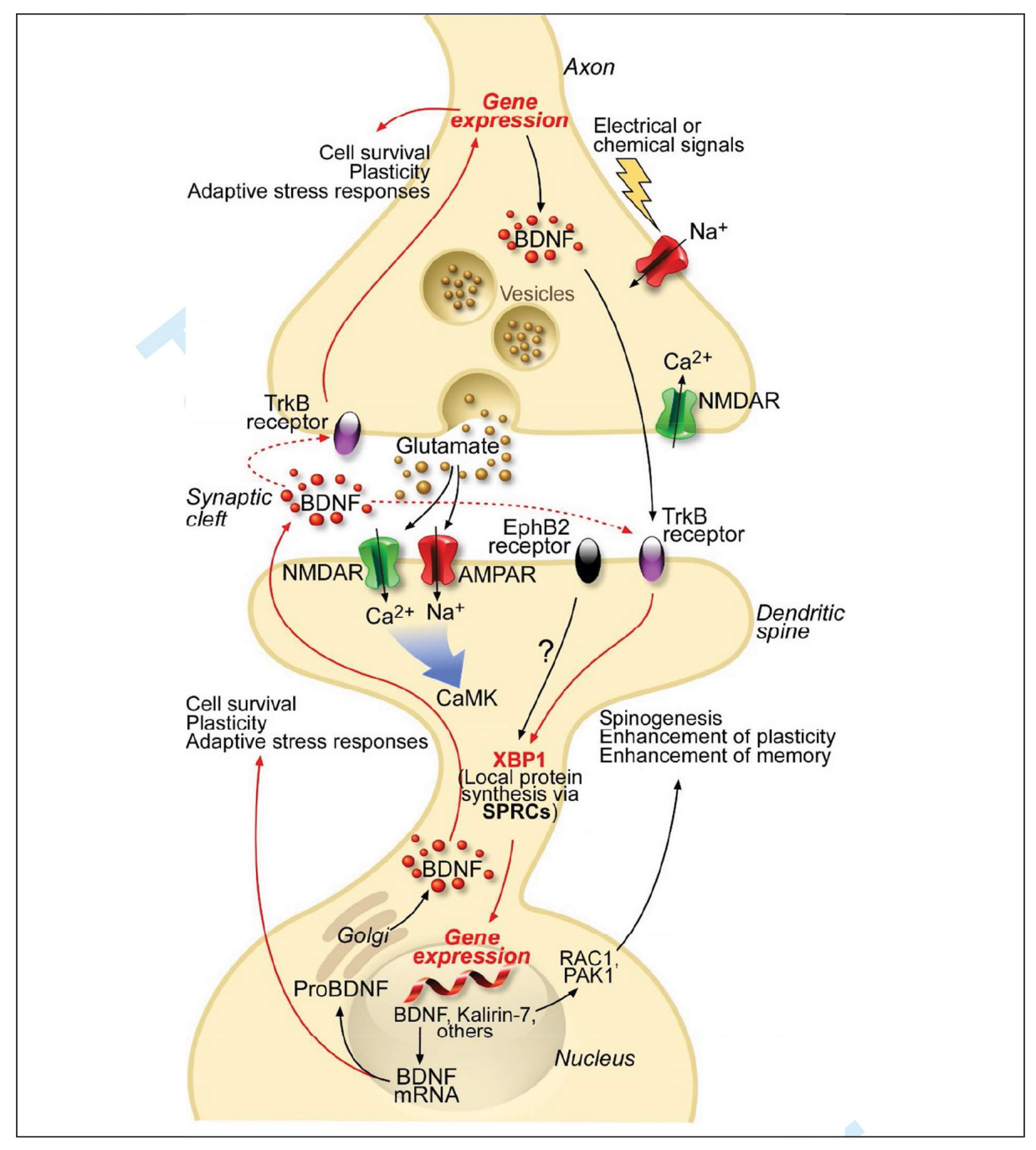

Figure 1. XBP1 signaling and neuronal plasticity. Presynaptic influx of $\mathrm{Ca}^{2+}$ releases glutamate into the synaptic cleft. This activates AMPA, EphB2 and NMDA receptors at the postsynaptic membrane that engages CaMKs and induces the transcription of the Bdnf gene. In parallel, XBPI can be locally synthetized within dendrites through SPRCs and transported into the nucleus to activate transcription of BDNF, Kalirin-7 and a myriad of other genes that are crucial for the survival and plasticity of neurons. $\mathrm{mBDNF}$ is released at synapses and activates TrkB receptors to recruit XBP1 and Kalirin-7, which controls spinogenesis through Rho-GTPases $R A C 1$ and PAK 1 , resulting in a positive activation loop. BDNF signaling also regulates synaptic transmission through control of neurotransmitter release at presynaptic terminals. Abbreviations: $A M P A(R)$, $\alpha$-amino-3-hydroxy-5-methyl-4-isoxazolepropionic acid (receptor); BDNF, brain-derived neurotrophic factor; CaMK, $\mathrm{Ca}^{2+}$ /calmodulin-dependent kinase; NMDA(R), N-methylD-aspartate (receptor); SPRCs, synapse-associated polyribosome complexes; EphB2, EphrinB2 receptor. Whether EphB2 acts upstream of XBP1 remains to be determined. Graphic adapted from (235). 


\section{CONCLUSION}

Collectively, there is overwhelming evidence that promoting the $\mathrm{BDNF} \rightarrow$ $\mathrm{XBP} 1 \rightarrow$ Kalirin-7 axis produces substantial protective effects on crucial neuronal circuitry involved in memory function by acting through both amyloid-dependent and -independent mechanisms. However, an important aspect to consider, besides proving a therapeutic concept in animal models and generating a drug to effectively translate that concept to clinics, is the challenge to efficaciously deliver a molecule to the brain due to constraints of bioavailability and the blood-brain barrier. In that regard, nanoparticle-based drug engineering (234) and/or MSC-based therapy (200), if proved efficient, could help overcome a rampant problem encountered in the pharmaceutical industry in general and lead to clinical trials with more positive outcomes. Hence, XBP1 and downstream pathways (see Figure 1) merit aggressive and thorough exploration as genuine therapeutic targets that could pave the way for more effective disease-modifying therapies in AD pathology.

\section{ACKNOWLEDGEMENTS}

This work has been developed and supported through the LABEX Excellence Laboratory Program Investment for the Future, Development of Innovative Strategies for a Transdisciplinary Approach to Alzheimer's Disease and the Hospital University Federation OncoAge. We wish to thank F. Aguila for preparation of graphics and the Conseil Départemental des Alpes Maritimes for financial support.

\section{DISCLOSURE}

The authors declare that they have no competing interests as defined by Molecular Medicine or other interests that might be perceived to influence the results and discussion reported in this paper.

\section{REFERENCES}

1. Selkoe DJ. (1991) The molecular pathology of Alzheimer's disease. Neuron. 6:487-98.

2. Mucke L, Selkoe DJ. (2012) Neurotoxicity of amyloid beta-protein: synaptic and network dysfunction. Cold Spring Harb. Perspect Med. 2:a006338.
3. Selkoe DJ. (2002) Alzheimer's disease is a synaptic failure. Science. 298:789-91.

4. Shankar GM, Walsh DM. (2009) Alzheimer's disease: synaptic dysfunction and Abeta. Mol. Neurodegener. 4:48.

5. Shankar GM, et al. (2008) Amyloid-beta protein dimers isolated directly from Alzheimer's brains impair synaptic plasticity and memory. Nat. Med 14:837-42.

6. Pozueta J, Lefort R, Shelanski ML. (2013) Synaptic changes in Alzheimer's disease and its models. Neuroscience. 251:51-65.

7. Dineley KT, Xia X, Bui D, Sweatt JD, Zheng H. (2002) Accelerated plaque accumulation, associative learning deficits, and up-regulation of alpha 7 nicotinic receptor protein in transgenic mice co-expressing mutant human presenilin 1 and amyloid precursor proteins. J. Biol. Chem. 277:22768-80.

8. Sturchler E, Galichet A, Weibel M, Leclerc E, Heizmann CW. (2008) Site-specific blockade of RAGE-Vd prevents amyloid-beta oligomer neurotoxicity. J. Neurosci. 28:5149-58.

9. Lauren J, Gimbel DA, Nygaard HB, Gilbert JW, Strittmatter SM. (2009) Cellular prion protein mediates impairment of synaptic plasticity by amyloid-beta oligomers. Nature. 457:1128-32.

10. Renner M, et al. (2010) Deleterious effects of amyloid beta oligomers acting as an extracellular scaffold for mGluR5. Neuron. 66:739-54.

11. Um JW, et al. (2013) Metabotropic glutamate receptor 5 is a coreceptor for Alzheimer abeta oligomer bound to cellular prion protein. Neuron. 79:887-902.

12. Zhao WQ, et al. (2008) Amyloid beta oligomers induce impairment of neuronal insulin receptors. FASEB J. 22:246-60.

13. Cisse M, et al. (2011) Reversing EphB2 depletion rescues cognitive functions in Alzheimer model. Nature. 469:47-52.

14. Cisse M, Checler F. (2015) Eph receptors: new players in Alzheimer's disease pathogenesis. Neurobiol. Dis. 73:137-49.

15. Kim T, et al. (2013) Human LilrB2 is a betaamyloid receptor and its murine homolog PirB regulates synaptic plasticity in an Alzheimer's model. Science. 341:1399-1404.

16. Knowles JK, et al. (2009) The p75 neurotrophin receptor promotes amyloid-beta(1-42)-induced neuritic dystrophy in vitro and in vivo. J. Neurosci. 29:10627-37.

17. Pujadas L, et al. (2014) Reelin delays amyloid-beta fibril formation and rescues cognitive deficits in a model of Alzheimer's disease. Nat. Commun. 5:3443.

18. Dinamarca MC, Rios JA, Inestrosa NC. (2012) Postsynaptic Receptors for Amyloid-beta Oligomers as Mediators of Neuronal Damage in Alzheimer's Disease. Front. Physiol. 3:464.

19. Cisse M, et al. (2016) The transcription factor $\mathrm{XBP} 1 \mathrm{~s}$ restores hippocampal synaptic plasticity and memory by control of the Kalirin-7 pathway in Alzheimer model. Mol. Psychiatry. 2016 Sep 20. doi: 10.1038/mp.2016.152 [Epub ahead of print].
20. Pietri M, et al. (2013) PDK1 decreases TACEmediated alpha-secretase activity and promotes disease progression in prion and Alzheimer's diseases. Nat. Med. 19:1124-31.

21. Roy DS, et al. (2016) Memory retrieval by activating engram cells in mouse models of early Alzheimer's disease. Nature. 531:508-12.

22. Yang X, et al. (2016) A novel mechanism of memory loss in Alzheimer's disease mice via the degeneration of entorhinal-CA1 synapses. Mol. Psychiatry 2016 Sep 27; doi: 10.1038/mp.2016.151 [Epub ahead of print].

23. Yoshida H, Matsui T, Yamamoto A, Okada T, Mori K. (2001) XBP1 mRNA is induced by ATF6 and spliced by IRE1 in response to ER stress to produce a highly active transcription factor. Cell. 107:881-91.

24. Acosta-Alvear D, et al. (2007) XBP1 controls diverse cell type- and condition-specific transcriptional regulatory networks. Mol. Cell. 27:53-66.

25. He Y, et al. (2010) Emerging roles for XBP1, a sUPeR transcription factor. Gene Expr. 15:13-25.

26. Martinez G, et al. (2016) Regulation of Memory Formation by the Transcription Factor XBP1. Cell Rep. 14:1382-94.

27. Glimcher LH. (2010) XBP1: the last two decades. Ann. Rheum. Dis. 69 Suppl 1:i67-71.

28. Dunys J, Duplan E, Checler F. (2014) The transcription factor X-box binding protein-1 in neurodegenerative diseases. Mol. Neurodegener. 9:35.

29. Yang J, et al. (2016) The Multiple Roles of XBP1 in Regulation of Glucose and Lipid Metabolism. Curr. Protein Pept. Sci. 2016 Jun 26 [Epub ahead of print].

30. Masaki T, Yoshida M, Noguchi S. (1999) Targeted disruption of CRE-binding factor TREB5 gene leads to cellular necrosis in cardiac myocytes at the embryonic stage. Biochem. Biophys. Res. Commun. 261:350-56.

31. Jurczak MJ, et al. (2012) Dissociation of inositolrequiring enzyme (IRE1alpha)-mediated c-Jun $\mathrm{N}$-terminal kinase activation from hepatic insulin resistance in conditional X-box-binding protein-1 (XBP1) knock-out mice. J. Biol. Chem. 287:2558-67.

32. Paschen W, Yatsiv I, Shoham S, Shohami E. (2004) Brain trauma induces $X$-box protein 1 processing indicative of activation of the endoplasmic reticulum unfolded protein response. J. Neurochem. 88:983-92.

33. Hayashi A, et al. (2007) The role of brain-derived neurotrophic factor (BDNF)-induced XBP1 splicing during brain development. J. Biol. Chem. 282:34525-34.

34. Barrett LE, et al. (2006) Region-directed phototransfection reveals the functional significance of a dendritically synthesized transcription factor. Nat. Methods. 3:455-60.

35. Di Nardo AA, et al. (2007) Dendritic localization and activity-dependent translation of Engrailed1 transcription factor. Mol. Cell. Neurosci. 35:230-36.

36. Steward O, Schuman EM. (2001) Protein synthesis at synaptic sites on dendrites. Annu. Rev. Neurosci. 24:299-325. 
37. Sutton MA, Schuman EM. (2005) Local translational control in dendrites and its role in longterm synaptic plasticity. J. Neurobiol. 64:116-31.

38. Steward O. (1983) Polyribosomes at the base of dendritic spines of central nervous system neurons-their possible role in synapse construction and modification. Cold Spring Harb. Symp. Quant. Biol. 48 Pt 2:745-59.

39. Steward O, Levy WB. (1982) Preferential localization of polyribosomes under the base of dendritic spines in granule cells of the dentate gyrus. J. Neurosci. 2:284-91.

40. De Strooper B, Vassar R, Golde T. (2010) The secretases: enzymes with therapeutic potential in Alzheimer disease. Nat. Rev. Neurol. 6:99-107.

41. Reinhardt S, et al. (2014) Unfolded protein response signaling by transcription factor XBP-1 regulates ADAM10 and is affected in Alzheimer's disease. FASEB J. 28:978-97.

42. Gerakis Y, Dunys J, Bauer C, Checler F. (2016) Abeta42 oligomers modulate beta-secretase through an XBP-1s-dependent pathway involving HRD1. Sci. Rep. 6:37436.

43. Yan R, Vassar R. (2014) Targeting the beta secretase BACE1 for Alzheimer's disease therapy. Lancet Neurol. 13:319-29.

44. Bailey JA, Maloney B, Ge YW, Lahiri DK. (2011) Functional activity of the novel Alzheimer's amyloid beta-peptide interacting domain (AbetaID) in the APP and BACE1 promoter sequences and implications in activating apoptotic genes and in amyloidogenesis. Gene. 488:13-22.

45. Maloney B, Lahiri DK. (2011) The Alzheimer's amyloid beta-peptide (Abeta) binds a specific DNA Abeta-interacting domain (AbetaID) in the APP, BACE1, and APOE promoters in a sequence-specific manner: characterizing a new regulatory motif. Gene. 488:1-12.

46. Sadleir KR, Vassar R. (2012) Cdk5 protein inhibition and Abeta42 increase BACE1 protein level in primary neurons by a post-transcriptional mechanism: implications of CDK5 as a therapeutic target for Alzheimer disease. J. Biol. Chem. 287:7224-35.

47. Wen Y, et al. (2008) Transcriptional regulation of beta-secretase by p25/cdk5 leads to enhanced amyloidogenic processing. Neuron. 57:680-90.

48. Barucker C, et al. (2014) Nuclear translocation uncovers the amyloid peptide Abeta42 as a regulator of gene transcription. J. Biol. Chem. 289:20182-91.

49. Tanokashira D, et al. (2015) LRP1 Downregulates the Alzheimer's beta-Secretase BACE1 by Modulating Its Intraneuronal Trafficking $(1,2,3)$. eNeuro. 2: 0006-15.

50. Kaneko M, et al. (2010) Loss of HRD1-mediated protein degradation causes amyloid precursor protein accumulation and amyloid-beta generation. J. Neurosci. 30:3924-32.

51. Munoz-Lobato F, et al. (2014) Protective role of DNJ-27/ERdj5 in Caenorhabditis elegans models of human neurodegenerative diseases. Antioxid. Redox. Signal 20:217-35.
52. Regitz C, Fitzenberger E, Mahn FL, Dussling LM, Wenzel U. (2016) Resveratrol reduces amyloid-beta (Abeta(1)(-)(4)(2))-induced paralysis through targeting proteostasis in an Alzheimer model of Caenorhabditis elegans. Eur. J. Nutr. 55:741-47.

53. Casas-Tinto S, et al. (2011) The ER stress factor XBP1s prevents amyloid-beta neurotoxicity. Hum. Mol. Genet. 20:2144-60.

54. van der Zee EA. (2015) Synapses, spines and kinases in mammalian learning and memory, and the impact of aging. Neurosci. Biobehav. Rev. 50:77-85.

55. Gipson CD, Olive MF. (2016) Structural and functional plasticity of dendritic spines: root or result of behavior? Genes Brain Behav. 16: 111-7.

56. Hering H, Sheng M. (2001) Dendritic spines: structure, dynamics and regulation. Nat. Rev. Neurosci. 2:880-88.

57. Sala C, Segal M. (2014) Dendritic spines: the locus of structural and functional plasticity. Physiol. Rev. 94:141-88.

58. Ryan TJ, Roy DS, Pignatelli M, Arons A, Tonegawa S. (2015) Memory. Engram cells retain memory under retrograde amnesia. Science. 348:1007-13.

59. Leuner B, Shors TJ. (2004) New spines, new memories. Mol. Neurobiol. 29:117-30.

60. Rampon C, et al. (2000) Effects of environmental enrichment on gene expression in the brain. Proc. Natl. Acad. Sci. USA. 97:12880-84.

61. Bettigole SE, Glimcher LH. (2015) Endoplasmic reticulum stress in immunity. Annu. Rev. Immunol. 33:107-38.

62. Chen X, et al. (2014) XBP1 promotes triplenegative breast cancer by controlling the HIF1alpha pathway. Nature. 508:103-07.

63. Sado M, et al. (2009) Protective effect against Parkinson's disease-related insults through the activation of XBP1. Brain Res. 1257:16-24.

64. Valdes P, et al. (2014) Control of dopaminergic neuron survival by the unfolded protein response transcription factor XBP1. Proc. Natl. Acad. Sci. USA. 111:6804-09.

65. Si L, Xu T, Wang F, Liu Q, Cui M. (2012) X-box-binding protein 1-modified neural stem cells for treatment of Parkinson's disease. Neural Regen. Res. 7:736-40.

66. Hayashi A, et al. (2009) Aberrant endoplasmic reticulum stress response in lymphoblastoid cells from patients with bipolar disorder. Int. J. Neuropsychopharmacol. 12:33-43.

67. So J, Warsh JJ, Li PP. (2007) Impaired endoplasmic reticulum stress response in B-lymphoblasts from patients with bipolar-I disorder. Biol. Psychiatry. 62:141-47.

68. Zuleta A, Vidal RL, Armentano D, Parsons G, Hetz C. (2012) AAV-mediated delivery of the transcription factor $\mathrm{XBP} 1 \mathrm{~s}$ into the striatum reduces mutant Huntingtin aggregation in a mouse model of Huntington's disease. Biochem. Biophys. Res. Commun. 420:558-63.
69. Hetz C, et al. (2008) Unfolded protein response transcription factor XBP-1 does not influence prion replication or pathogenesis. Proc. Natl. Acad. Sci. USA. 105:757-62.

70. Herring BE, Nicoll RA. (2016) Long-Term Potentiation: From CaMKII to AMPA Receptor Trafficking. Annu. Rev. Physiol. 78:351-65.

71. Ma XM, et al. (2008) Kalirin-7 is required for synaptic structure and function. J. Neurosci. 28:12368-82.

72. Penzes P, et al. (2003) Rapid induction of dendritic spine morphogenesis by trans-synaptic ephrinB-EphB receptor activation of the Rho-GEF kalirin. Neuron. 37:263-74.

73. Penzes P, Jones KA. (2008) Dendritic spine dynamics - a key role for kalirin-7. Trends Neurosci. 31:419-27.

74. Murata Y, Constantine-Paton M. (2013) Postsynaptic density scaffold SAP102 regulates cortical synapse development through EphB and PAK signaling pathway. J. Neurosci. 33:5040-52.

75. Ma XM, Huang J, Wang Y, Eipper BA, Mains RE. (2003) Kalirin, a multifunctional Rho guanine nucleotide exchange factor, is necessary for maintenance of hippocampal pyramidal neuron dendrites and dendritic spines. J. Neurosci. 23:10593-603.

76. Iwata N, et al. (2001) Metabolic regulation of brain Abeta by neprilysin. Science. 292:1550-52.

77. Leissring MA, et al. (2003) Enhanced proteolysis of beta-amyloid in APP transgenic mice prevents plaque formation, secondary pathology, and premature death. Neuron. 40:1087-93.

78. Mueller-Steiner S, et al. (2006) Antiamyloidogenic and neuroprotective functions of cathepsin B: implications for Alzheimer's disease. Neuron. 51:703-14.

79. Saito T, et al. (2005) Somatostatin regulates brain amyloid beta peptide Abeta42 through modulation of proteolytic degradation. Nat. Med. 11:434-39.

80. Citron M. (2004) Strategies for disease modification in Alzheimer's disease. Nat. Rev. Neurosci. 5:677-85.

81. Citron M. (2010) Alzheimer's disease: strategies for disease modification. Nat. Rev. Drug. Discov. 9:387-98.

82. Checler F. (1995) Processing of the beta-amyloid precursor protein and its regulation in Alzheimer's disease. J. Neurochem. 65:1431-44.

83. Bellot A, et al. (2014) The structure and function of actin cytoskeleton in mature glutamatergic dendritic spines. Brain Res. 1573:1-16.

84. Frankfurt M, Luine V. (2015) The evolving role of dendritic spines and memory: Interaction(s) with estradiol. Horm. Behav. 74:28-36.

85. Lu B, Nagappan G, Guan X, Nathan PJ, Wren P. (2013) BDNF-based synaptic repair as a disease-modifying strategy for neurodegenerative diseases. Nat. Rev. Neurosci. 14:401-16.

86. Lai KO, et al. (2012) TrkB phosphorylation by Cdk5 is required for activity-dependent 
structural plasticity and spatial memory. Nat. Neurosci. 15:1506-15.

87. Miller MB, Yan Y, Eipper BA, Mains RE. (2013) Neuronal Rho GEFs in synaptic physiology and behavior. Neuroscientist. 19:255-73.

88. Lauritzen I, et al. (2016) Intraneuronal aggregation of the beta-CTF fragment of APP (C99) induces Abeta-independent lysosomal-autophagic pathology. Acta Neuropathol. 132:257-76.

89. Morris M, Maeda S, Vossel K, Mucke L. (2011) The many faces of tau. Neuron. 70:410-26.

90. Gilman S, et al. (2005) Clinical effects of Abeta immunization (AN1792) in patients with AD in an interrupted trial. Neurology. 64:1553-62.

91. Mullard A. (2012) Sting of Alzheimer's failures offset by upcoming prevention trials. Nat. Rev. Drug. Discov. 11:657-60.

92. Lardenoije R, et al. (2015) The epigenetics of aging and neurodegeneration. Prog. Neurobiol. 131:21-64.

93. Maloney B, Lahiri DK. (2016) Epigenetics of dementia: understanding the disease as a transformation rather than a state. Lancet Neurol. 15:760-74.

94. Cholewa-Waclaw J, et al. (2016) The Role of Epigenetic Mechanisms in the Regulation of Gene Expression in the Nervous System. J. Neurosci. 36:11427-34.

95. Shah K, Lahiri DK. (2016) A Tale of the Good and Bad: Remodeling of the Microtubule Network in the Brain by Cdk5. Mol. Neurobiol. 2016 Mar 5; doi:10.1007/s12035-016-9792-7 [Epub ahead of print].

96. Shah K, Lahiri DK. (2014) Cdk5 activity in the brain: multiple paths of regulation. J. Cell Sci. 127:2391-2400.

97. Jin X, et al. (2016) Phosphorylation of CRMP2 by Cdk5 Regulates Dendritic Spine Development of Cortical Neuron in the Mouse Hippocampus. Neural Plast. 2016:6790743.

98. Mishiba T, et al. (2014) Cdk5/p35 functions as a crucial regulator of spatial learning and memory. Mol. Brain. 7:82.

99. Plattner F, et al. (2014) Memory enhancement by targeting Cdk5 regulation of NR2B. Neuron. 81:1070-83.

100. Li L, Zhang C, Zi X, Tu Q, Guo K. (2015) Epigenetic modulation of Cdk5 contributes to memory deficiency induced by amyloid fibrils. Exp. Brain Res. 233:165-73.

101. Patrick GN, et al. (1999) Conversion of p35 to p25 deregulates Cdk5 activity and promotes neurodegeneration. Nature. 402:615-22.

102. Shukla V, Skuntz S, Pant HC. (2012) Deregulated Cdk5 activity is involved in inducing Alzheimer's disease. Arch. Med. Res. 43:655-62.

103. Shukla V, et al. (2013) A truncated peptide from p35, a Cdk5 activator, prevents Alzheimer's disease phenotypes in model mice. FASEB J. 27:174-86.

104. Hayashi A, Kasahara T, Kametani M, Kato T. (2008) Attenuated BDNF-induced upregulation of GABAergic markers in neurons lacking Xbp1. Biochem. Biophys. Res. Commun. 376:758-63.
105. Bothwell M. (2016) Recent advances in understanding neurotrophin signaling [version 1; referees: 2 approved]. F1000Res (F1000 Faculty Rev):1885 (doi: 10.12688/f1000research.8434.1)

106. Kang H, Schuman EM. (1995) Long-lasting neurotrophin-induced enhancement of synaptic transmission in the adult hippocampus. Science. 267:1658-62.

107. Figurov A, Pozzo-Miller LD, Olafsson P, Wang T, Lu B. (1996) Regulation of synaptic responses to high-frequency stimulation and LTP by neurotrophins in the hippocampus. Nature. 381:706-09.

108. Messaoudi E, Bardsen K, Srebro B, Bramham CR. (1998) Acute intrahippocampal infusion of BDNF induces lasting potentiation of synaptic transmission in the rat dentate gyrus. J. Neurophysiol. 79:496-99.

109. Patterson SL, et al. (1996) Recombinant BDNF rescues deficits in basal synaptic transmission and hippocampal LTP in BDNF knockout mice. Neuron. 16:1137-45.

110. Akaneya Y, Tsumoto T, Kinoshita S, Hatanaka H. (1997) Brain-derived neurotrophic factor enhances long-term potentiation in rat visual cortex. J. Neurosci. 17:6707-16.

111. Huber KM, Sawtell NB, Bear MF. (1998) Brain-derived neurotrophic factor alters the synaptic modification threshold in visual cortex. Neuropharmacology. 37:571-79.

112. Tanaka J, et al. (2008) Protein synthesis and neurotrophin-dependent structural plasticity of single dendritic spines. Science. 319:1683-87.

113. Maletic-Savatic M, Malinow R, Svoboda K. (1999) Rapid dendritic morphogenesis in CA1 hippocampal dendrites induced by synaptic activity. Science. 283:1923-27.

114. Engert F, Bonhoeffer T. (1999) Dendritic spine changes associated with hippocampal longterm synaptic plasticity. Nature. 399:66-70.

115. Ji Y, et al. (2010) Acute and gradual increases in BDNF concentration elicit distinct signaling and functions in neurons. Nat. Neurosci. 13:302-09.

116. Tyler WJ, Pozzo-Miller L. (2003) Miniature synaptic transmission and BDNF modulate dendritic spine growth and form in rat CA1 neurones. J. Physiol. 553:497-509.

117. Aguado F, et al. (2003) BDNF regulates spontaneous correlated activity at early developmental stages by increasing synaptogenesis and expression of the $\mathrm{K}+/ \mathrm{Cl}$ - co-transporter KCC2. Development. 130:1267-80.

118. Otal R, Martinez A, Soriano E. (2005) Lack of TrkB and TrkC signaling alters the synaptogenesis and maturation of mossy fiber terminals in the hippocampus. Cell Tissue Res. 319:349-58.

119. Singh B, et al. (2006) Altered balance of glutamatergic/GABAergic synaptic input and associated changes in dendrite morphology after BDNF expression in BDNF-deficient hippocampal neurons. J. Neurosci. 26:7189-7200.

120. Mu JS, Li WP, Yao ZB, Zhou XF. (1999) Deprivation of endogenous brain-derived neurotrophic factor results in impairment of spatial learning and memory in adult rats. Brain. Res 835:259-65.

121. Ma YL, Wang HL, Wu HC, Wei CL, Lee EH. (1998) Brain-derived neurotrophic factor antisense oligonucleotide impairs memory retention and inhibits long-term potentiation in rats. Neuroscience. 82:957-67.

122. Linnarsson S, Bjorklund A, Ernfors P. (1997) Learning deficit in BDNF mutant mice. Eur. J. Neurosci. 9:2581-87.

123. Minichiello L, et al. (1999) Essential role for TrkB receptors in hippocampus-mediated learning. Neuron. 24:401-14.

124. Chen $X$, et al. (2005) A chemical-genetic approach to studying neurotrophin signaling. Neuron. 46:13-21.

125. Alonso M, Vianna MR, Izquierdo I, Medina JH. (2002) Signaling mechanisms mediating BDNF modulation of memory formation in vivo in the hippocampus. Cell Mol. Neurobiol. 22:663-74.

126. Koponen E, et al. (2004) Transgenic mice overexpressing the full-length neurotrophin receptor trkB exhibit increased activation of the trkBPLCgamma pathway, reduced anxiety, and facilitated learning. Mol. Cell. Neurosci. 26:166-81.

127. Pang PT, et al. (2004) Cleavage of proBDNF by tPA/plasmin is essential for long-term hippocampal plasticity. Science. 306:487-91.

128. Soliman F, et al. (2010) A genetic variant BDNF polymorphism alters extinction learning in both mouse and human. Science. 327:863-66.

129. Meng C, He Z, Xing D. (2013) Low-level laser therapy rescues dendrite atrophy via upregulating BDNF expression: implications for Alzheimer's disease. J. Neurosci. 33:13505-17.

130. Fritsch B, et al. (2010) Direct current stimulation promotes BDNF-dependent synaptic plasticity: potential implications for motor learning. Neuron. 66:198-204.

131. Zimmermann T, Remmers F, Lutz B, Leschik J. (2016) ESC-Derived BDNF-Overexpressing Neural Progenitors Differentially Promote Recovery in Huntington's Disease Models by Enhanced Striatal Differentiation. Stem Cell Reports. 7:693-706.

132. Zhao X, et al. (2016) TRiC subunits enhance BDNF axonal transport and rescue striatal atrophy in Huntington's disease. Proc. Natl. Acad. Sci. USA. 113:E5655-64.

133. Sun MK, Hongpaisan J, Alkon DL. (2016) Rescue of Synaptic Phenotypes and Spatial Memory in Young Fragile X Mice. J. Pharmacol. Exp. Ther. 357:300-10.

134. Nagahara AH, Tuszynski MH. (2011) Potential therapeutic uses of BDNF in neurological and psychiatric disorders. Nat. Rev. Drug. Discov. 10:209-19.

135. Zeng Y, Zhao D, Xie CW. (2010) Neurotrophins enhance CaMKII activity and rescue amyloid-beta-induced deficits in hippocampal synaptic plasticity. J. Alzheimers Dis. 21:823-31. 
136. Zhang L, et al. (2015) Brain-derived neurotrophic factor ameliorates learning deficits in a rat model of Alzheimer's disease induced by abeta1-42. PLoS One. 10: e0122415.

137. Nagahara AH, et al. (2009) Neuroprotective effects of brain-derived neurotrophic factor in rodent and primate models of Alzheimer's disease. Nat. Med. 15:331-37.

138. Egan MF, et al. (2003) The BDNF val66met polymorphism affects activity-dependent secretion of BDNF and human memory and hippocampal function. Cell. 112:257-69.

139. Miyajima F, et al. (2008) Brain-derived neurotrophic factor polymorphism Val66Met influences cognitive abilities in the elderly. Genes Brain Behav. 7:411-17.

140. Beste C, et al. (2010) The role of the BDNF Val$66 \mathrm{Met}$ polymorphism for the synchronization of error-specific neural networks. J. Neurosci. 30:10727-33.

141. Liu J, et al. (2012) Brain-derived neurotrophic factor (BDNF) genetic polymorphism greatly increases risk of leucine-rich repeat kinase 2 (LRRK2) for Parkinson's disease. Parkinsonism Relat. Disord. 18:140-43.

142. Parsian A, Sinha R, Racette B, Zhao JH, Perlmutter JS. (2004) Association of a variation in the promoter region of the brain-derived neurotrophic factor gene with familial Parkinson's disease. Parkinsonism Relat. Disord. 10:213-19.

143. Borroni B, et al. (2009) BDNF genetic variations increase the risk of Alzheimer's disease-related depression. J. Alzheimers Dis. 18:867-75.

144. Borroni B, et al. (2009) Role of BDNF Val66Met functional polymorphism in Alzheimer's disease-related depression. Neurobiol. Aging. 30:1406-12.

145. Caccamo A, Maldonado MA, Bokov AF, Majumder S, Oddo S. (2010) CBP gene transfer increases BDNF levels and ameliorates learning and memory deficits in a mouse model of Alzheimer's disease. Proc. Natl. Acad. Sci. USA. 107:22687-92.

146. Liu SY, et al. (2013) Polymorphism-116C/G of human X-box-binding protein 1 promoter is associated with risk of Alzheimer's disease. CNS Neurosci. Ther. 19:229-34.

147. Kiraly DD, et al. (2010) Behavioral and morphological responses to cocaine require kalirin7. Biol. Psychiatry 68:249-55.

148. Xie Z, et al. (2011) Hippocampal phenotypes in kalirin-deficient mice. Mol. Cell. Neurosci. 46:45-54.

149. Mandela P, et al. (2012) Kalirin plays key roles within and outside of the nervous system. BMC Neurosci. 13:136.

150. Lemtiri-Chlieh F, et al. (2011) Kalirin-7 is necessary for normal NMDA receptor-dependent synaptic plasticity. BMC Neurosci. 12:126.

151. Kiraly DD, Lemtiri-Chlieh F, Levine ES, Mains RE, Eipper BA. (2011) Kalirin binds the NR2B subunit of the NMDA receptor, altering its synaptic localization and function. J. Neurosci. 31:12554-65.
152. Tolias KF, et al. (2005) The Rac1-GEF Tiam 1 couples the NMDA receptor to the activity-dependent development of dendritic arbors and spines. Neuron. 45:525-38.

153. Murakoshi H, Wang H, Yasuda R. (2011) Local, persistent activation of Rho GTPases during plasticity of single dendritic spines. Nature. 472:100-04.

154. McAvoy KM, et al. (2016) Modulating Neuronal Competition Dynamics in the Dentate Gyrus to Rejuvenate Aging Memory Circuits. Neuron. 91:1356-73.

155. Haditsch U, et al. (2009) A central role for the small GTPase Rac1 in hippocampal plasticity and spatial learning and memory. Mol. Cell. Neurosci. 41:409-19.

156. Jiang L, et al. (2016) Inhibition of Rac1 Activity in the Hippocampus Impairs the Forgetting of Contextual Fear Memory. Mol. Neurobiol. 53:1247-53.

157. Hedrick NG, et al. (2016) Rho GTPase complementation underlies BDNF-dependent homoand heterosynaptic plasticity. Nature. 538: 104-8.

158. Yan Y, Eipper BA, Mains RE. (2016) Kalirin is required for BDNF-TrkB stimulated neurite outgrowth and branching. Neuropharmacology. 107:227-38.

159. Poon WW, et al. (2011) Beta-amyloid impairs axonal BDNF retrograde trafficking. Neurobiol. Aging. 32:821-33.

160. Poon WW, et al. (2013) Beta-amyloid (Abeta) oligomers impair brain-derived neurotrophic factor retrograde trafficking by down-regulating ubiquitin C-terminal hydrolase, UCH-L1. J Biol. Chem. 288:16937-48.

161. Garzon DJ, Fahnestock M. (2007) Oligomeric amyloid decreases basal levels of brain-derived neurotrophic factor (BDNF) mRNA via specific downregulation of BDNF transcripts IV and V in differentiated human neuroblastoma cells. J. Neurosci. 27:2628-35.

162. Sen A, Nelson TJ, Alkon DL. (2015) ApoE4 and Abeta Oligomers Reduce BDNF Expression via HDAC Nuclear Translocation. J. Neurosci. 35:7538-51.

163. Jeronimo-Santos A, et al. (2015) Dysregulation of TrkB Receptors and BDNF Function by Amyloid-beta Peptide is Mediated by Calpain. Cereb. Cortex. 25:3107-21.

164. Tong L, Balazs R, Thornton PL, Cotman CW. (2004) Beta-amyloid peptide at sublethal concentrations downregulates brain-derived neurotrophic factor functions in cultured cortical neurons. J. Neurosci. 24:6799-6809.

165. Wang DC, Chen SS, Lee YC, Chen TJ. (2006) Amyloid-beta at sublethal level impairs BDNF-induced arc expression in cortical neurons. Neurosci. Lett. 398:78-82.

166. Ciaramella A, et al. (2013) The stimulation of dendritic cells by amyloid beta $1-42$ reduces BDNF production in Alzheimer's disease patients. Brain Behav. Immun. 32:29-32.
167. Lourenco MV, et al. (2013) TNF-alpha mediates PKR-dependent memory impairment and brain IRS-1 inhibition induced by Alzheimer's beta-amyloid oligomers in mice and monkeys. Cell Metab. 18:831-43.

168. Dumitriu D, et al. (2010) Selective changes in thin spine density and morphology in monkey prefrontal cortex correlate with aging-related cognitive impairment. J. Neurosci. 30:7507-15.

169. Chen $Y$, et al. (2010) Correlated memory defects and hippocampal dendritic spine loss after acute stress involve corticotropin-releasing hormone signaling. Proc. Natl. Acad. Sci. USA. 107: 13123-28.

170. Diano S, et al. (2006) Ghrelin controls hippocampal spine synapse density and memory performance. Nat. Neurosci. 9:381-88.

171. Rogers JT, et al. (2011) Reelin supplementation enhances cognitive ability, synaptic plasticity, and dendritic spine density. Learn Mem. 18:558-64.

172. Jacome LF, et al. (2016) Gonadal Hormones Rapidly Enhance Spatial Memory and Increase Hippocampal Spine Density in Male Rats. Endocrinology. 157:1357-62.

173. Eilam-Stock T, Serrano P, Frankfurt M, Luine V. (2012) Bisphenol-A impairs memory and reduces dendritic spine density in adult male rats. Behav. Neurosci. 126:175-85.

174. Rodriguez GA, Burns MP, Weeber EJ, Rebeck GW. (2013) Young APOE4 targeted replacement mice exhibit poor spatial learning and memory, with reduced dendritic spine density in the medial entorhinal cortex. Learn Mem. 20:256-66.

175. Parihar MS, Brewer GJ. (2010) Amyloid-beta as a modulator of synaptic plasticity. J. Alzheimers Dis. 22:741-63.

176. Suberbielle E, et al. (2015) DNA repair factor BRCA1 depletion occurs in Alzheimer brains and impairs cognitive function in mice. Nat. Commun. 6:8897.

177. Singer O, et al. (2005) Targeting BACE1 with siRNAs ameliorates Alzheimer disease neuropathology in a transgenic model. Nat. Neurosci. 8:1343-49.

178. Villeda SA, et al. (2014) Young blood reverses age-related impairments in cognitive function and synaptic plasticity in mice. Nat. Med. 20:659-63.

179. Guan JS, et al. (2009) HDAC2 negatively regulates memory formation and synaptic plasticity. Nature. 459:55-60.

180. Alcantara-Gonzalez F, et al. (2010) Enhanced dendritic spine number of neurons of the prefrontal cortex, hippocampus, and nucleus accumbens in old rats after chronic donepezil administration. Synapse. 64:786-93.

181. D'Amelio M, et al. (2011) Caspase-3 triggers early synaptic dysfunction in a mouse model of Alzheimer's disease. Nat. Neurosci. 14:69-76.

182. Dolan BM, et al. (2013) Rescue of fragile $X$ syndrome phenotypes in Fmr1 KO mice by the small-molecule PAK inhibitor FRAX486. Proc. Natl. Acad. Sci. USA. 110:5671-76. 
183. Cavallucci V, et al. (2013) Calcineurin inhibition rescues early synaptic plasticity deficits in a mouse model of Alzheimer's disease. Neuromolecular Med. 15:541-48.

184. Bero AW, et al. (2014) Early remodeling of the neocortex upon episodic memory encoding. Proc. Natl. Acad. Sci. USA. 111:11852-57.

185. Lepousez G, et al. (2014) Olfactory learning promotes input-specific synaptic plasticity in adult-born neurons. Proc. Natl. Acad. Sci. USA. 111:13984-89.

186. Spangenberg EE, et al. (2016) Eliminating microglia in Alzheimer's mice prevents neuronal loss without modulating amyloid-beta pathology. Brain. 139:1265-81.

187. Fischer A, Sananbenesi F, Wang X, Dobbin M, Tsai LH. (2007) Recovery of learning and memory is associated with chromatin remodelling. Nature. 447:178-82.

188. Yiu AP, Rashid AJ, Josselyn SA. (2011) Increasing CREB function in the CA1 region of dorsal hippocampus rescues the spatial memory deficits in a mouse model of Alzheimer's disease. Neuropsychopharmacology. 36:2169-86.

189. Cole CJ, et al. (2012) MEF2 negatively regulates learning-induced structural plasticity and memory formation. Nat. Neurosci. 15:1255-64.

190. Wang XD, et al. (2013) Nectin-3 links CRHR1 signaling to stress-induced memory deficits and spine loss. Nat. Neurosci. 16:706-13.

191. Richetin K, et al. (2015) Genetic manipulation of adult-born hippocampal neurons rescues memory in a mouse model of Alzheimer's disease. Brain. 138:440-55.

192. Fol R, et al. (2016) Viral gene transfer of APPsalpha rescues synaptic failure in an Alzheimer's disease mouse model. Acta Neuropathol. 131:247-66.

193. Zhu XN, et al. (2016) Amygdala EphB2 Signaling Regulates Glutamatergic Neuron Maturation and Innate Fear. J. Neurosci. 36:10151-62.

194. Jimenez-Mateos EM, et al. (2012) Silencing microRNA-134 produces neuroprotective and prolonged seizure-suppressive effects. Nat. Med. 18:1087-94.

195. Busquets-Garcia A, et al. (2013) Targeting the endocannabinoid system in the treatment of fragile X syndrome. Nat. Med. 19:603-07.

196. Terada K, et al. (2014) Fluvoxamine moderates reduced voluntary activity following chronic dexamethasone infusion in mice via recovery of BDNF signal cascades. Neurochem. Int. 69:9-13.

197. Benraiss A, et al. (2012) Sustained induction of neuronal addition to the adult rat neostriatum by AAV4-delivered noggin and BDNF. Gene Ther. 19:483-93.

198. Kordower JH. (2016) AAV2-Neurturin for Parkinson's Disease: What Lessons Have We Learned? Methods Mol. Biol. 1382:485-90.
199. Fink KD, et al. (2015) Developing stem cell therapies for juvenile and adult-onset Huntington's disease. Regen. Med. 10:623-46.

200. Deng P, et al. (2016) Engineered BDNF producing cells as a potential treatment for neurologic disease. Expert Opin. Biol. Ther. 16:1025-33.

201. Jiang D, Niwa M, Koong AC. (2015) Targeting the IRE1alpha-XBP1 branch of the unfolded protein response in human diseases. Semin. Cancer Biol. 33:48-56.

202. Kim HJ, Cho HK, Kwon YH. (2008) Synergistic induction of ER stress by homocysteine and beta-amyloid in SH-SY5Y cells. J. Nutr. Biochem. 19:754-61.

203. Costa RO, Ferreiro E, Oliveira CR, Pereira CM. (2013) Inhibition of mitochondrial cytochrome c oxidase potentiates Abeta-induced ER stress and cell death in cortical neurons. Mol. Cell. Neurosci. 52:1-8.

204. Castillo-Carranza DL, et al. (2012) Differential activation of the ER stress factor XBP1 by oligomeric assemblies. Neurochem. Res. 37:1707-17.

205. Sanches M, et al. (2014) Structure and mechanism of action of the hydroxy-aryl-aldehyde class of IRE1 endoribonuclease inhibitors. Nat. Commun. 5:4202.

206. Cross BC, et al. (2012) The molecular basis for selective inhibition of unconventional mRNA splicing by an IRE1-binding small molecule. Proc. Natl. Acad. Sci. USA. 109: E869-78.

207. Romero-Ramirez L, et al. (2009) X box-binding protein 1 regulates angiogenesis in human pancreatic adenocarcinomas. Transl. Oncol. 2:31-38.

208. Suganthy N, Devi KP, Nabavi SF, Braidy N, Nabavi SM. (2016) Bioactive effects of quercetin in the central nervous system: Focusing on the mechanisms of actions. Biomed. Pharmacother. 84:892-08.

209. Yang EJ, Kim GS, Kim JA, Song KS. (2013) Protective effects of onion-derived quercetin on glutamate-mediated hippocampal neuronal cell death. Pharmacogn. Mag. 9:302-08.

210. Paula-Lima AC, Brito-Moreira J, Ferreira ST. (2013) Deregulation of excitatory neurotransmission underlying synapse failure in Alzheimer's disease. J. Neurochem. 126:191-202.

211. Li S, et al. (2009) Soluble oligomers of amyloid Beta protein facilitate hippocampal long-term depression by disrupting neuronal glutamate uptake. Neuron. 62:788-801.

212. Hsieh $\mathrm{H}$, et al. (2006) AMPAR removal underlies Abeta-induced synaptic depression and dendritic spine loss. Neuron. 52:831-43.

213. Annweiler C, Brugg B, Peyrin JM, Bartha R, Beauchet O. (2014) Combination of memantine and vitamin $\mathrm{D}$ prevents axon degeneration induced by amyloid-beta and glutamate. Neurobiol. Aging. 35:331-35.

214. Thomas SJ, Grossberg GT. (2009) Memantine: a review of studies into its safety and efficacy in treating Alzheimer's disease and other dementias. Clin. Interv. Aging. 4:367-77.
215. de Boer VC, de Goffau MC, Arts IC, Hollman PC, Keijer J. (2006) SIRT1 stimulation by polyphenols is affected by their stability and metabolism. Mech. Ageing Dev. 127:618-27.

216. Min SW, et al. (2010) Acetylation of tau inhibits its degradation and contributes to tauopathy. Neuron. 67:953-66.

217. Lu J, et al. (2010) Quercetin activates AMPactivated protein kinase by reducing PP2C expression protecting old mouse brain against high cholesterol-induced neurotoxicity. J. Pathol. 222:199-212.

218. Johnson JL, Rupasinghe SG, Stefani F, Schuler MA, Gonzalez de Mejia E. (2011) Citrus flavonoids luteolin, apigenin, and quercetin inhibit glycogen synthase kinase-3beta enzymatic activity by lowering the interaction energy within the binding cavity. J. Med. Food. 14:325-33.

219. Maeda S, Mucke L. (2016) Tau Phosphorylation: Much More than a Biomarker. Neuron. 92:265-67.

220. Lasagna-Reeves CA, et al. (2016) Reduction of Nuak1 Decreases Tau and Reverses Phenotypes in a Tauopathy Mouse Model. Neuron. 92:407-18.

221. Regitz C, Dussling LM, Wenzel U. (2014) Amyloid-beta (Abeta(1)(-)(4)(2))-induced paralysis in Caenorhabditis elegans is inhibited by the polyphenol quercetin through activation of protein degradation pathways. Mol. Nutr. Food Res. 58:1931-40.

222. Ono K, et al. (2003) Potent anti-amyloidogenic and fibril-destabilizing effects of polyphenols in vitro: implications for the prevention and therapeutics of Alzheimer's disease. J. Neurochem. 87:172-81.

223. Qu L, Liang X, Gu B, Liu W. (2014) Quercetin alleviates high glucose-induced Schwann cell damage by autophagy. Neural Regen. Res. 9:1195-1203.

224. Shimmyo Y, Kihara T, Akaike A, Niidome T, Sugimoto H. (2008) Flavonols and flavones as BACE-1 inhibitors: structure-activity relationship in cell-free, cell-based and in silico studies reveal novel pharmacophore features. Biochim. Biophys. Acta. 1780:819-25.

225. Nakajima K, Niisato N, Marunaka Y. (2011) Quercetin stimulates NGF-induced neurite outgrowth in PC12 cells via activation of $\mathrm{Na}(+) / \mathrm{K}(+) / 2 \mathrm{Cl}(-)$ cotransporter. Cell Physiol. Biochem. 28:147-56.

226. Yao RQ, et al. (2012) Quercetin attenuates cell apoptosis in focal cerebral ischemia rat brain via activation of BDNF-TrkB-PI3K/Akt signaling pathway. Neurochem. Res. 37:2777-86.

227. Wang DM, et al. (2014) Effects of long-term treatment with quercetin on cognition and mitochondrial function in a mouse model of Alzheimer's disease. Neurochem. Res. 39:1533-43.

228. Subash S, et al. (2014) Consumption of fig fruits grown in Oman can improve memory, anxiety, and learning skills in a transgenic mice model of Alzheimer's disease. Nutr. Neurosci. 19: $475-83$. 
229. Sabogal-Guaqueta AM, et al. (2015) The flavonoid quercetin ameliorates Alzheimer's disease pathology and protects cognitive and emotional function in aged triple transgenic Alzheimer's disease model mice. Neuropharmacology. 93:134-45.

230. Hayakawa M, et al. (2015) Quercetin reduces eIF2alpha phosphorylation by GADD34 induction. Neurobiol. Aging. 36:2509-18.

231. Kong Y, et al. (2016) Quercetin ameliorates Abeta toxicity in Drosophila AD model by modulating cell cycle-related protein expression. Oncotarget. 7: 67716-31.

232. Nakagawa $T$, et al. (2016) Improvement of memory recall by quercetin in rodent contextual fear conditioning and human early-stage Alzheimer's disease patients. Neuroreport. 27:671-76.

233. Broman-Fulks JJ, Canu WH, Trout KL, Nieman DC. (2012) The effects of quercetin supplementation on cognitive functioning in a community sample: a randomized, placebocontrolled trial. Ther. Adv. Psychopharmacol. 2:131-38.

234. Sun D, et al. (2016) Design of PLGA-functionalized quercetin nanoparticles for potential use in Alzheimer's disease. Colloids Surf. B Biointerfaces. 148:116-29.

235. Marosi K, Mattson MP. (2014) BDNF mediates adaptive brain and body responses to energetic challenges. Trends Endocrinol. Metab. 25:89-98.

Cite this article as: Cissé M, Duplan E, and Checler F. (2016) The transcription factor XBP1 in memory and cognition: implications in Alzheimer's disease. Mol. Med. 22:905-17. 